|| ISSN(online): 2589-8698 || ISSN(print): 2589-868X || International Journal of Medical and Biomedical Studies

Available Online at www.ijmbs.info

PubMed (National Library of Medicine ID: 101738825)

Index Copernicus Value 2018: 75.71

Volume 3, Issue 4; April: 2019; Page No. 231-236

\title{
ASSESSMENT OF THE EFFECTIVENESS OF HOMOEOPATHIC REMEDIES IN IMPROVING QUALITY OF LIFE OF CHRONIC LOW BACK PAIN: A PROSPECTIVE STUDY.
}

\author{
Dr. Indrajeet P. Shah \\ Department of Medicine, MNR Homoeopathic Medical College and Hospital, Sangareddy, Telangana
}

Article Info: Received 11 April 2019; Accepted 29 April. 2019

Cite this article as: P. Shah, Dr. I. (2019). ASSESSMENT OF THE EFFECTIVENESS OF HOMOEOPATHIC REMEDIES IN IMPROVING QUALITY OF LIFE OF CHRONIC LOW BACK PAIN: A PROSPECTIVE STUDY. International Journal of Medical and Biomedical Studies, 3(4).

DOI: https://doi.org/10.32553/ijmbs.v3i4.222

Address for Correspondence: Dr. Indrajeet P. Shah, Department of Medicine, MNR Homoeopathic Medical College and Hospital, Sangareddy, Telangana

Conflict of interest: No conflict of interest.

\section{Abstract}

AIM \& OBJECTIVE: The main purpose of this study was to assess the results of Homoeopathic treatment in the management of chronic low back pain and to provide evidence of impact on the patients in terms of health status and health related quality of life.

Methods: It was a single-centred, prospective, interventional study conducted at MNR UHC Homeopathic OPD in Sangareddy, from Dec 2018 to Feb 2019. At 0 day (Baseline) and 90 days standardized measuring scale were used like, Oswestry Disability Index, SF-12 questionnaire. Homoeopathic treatment was given to patients suffering from chronic low back pain.

Results: Estimation of the Oswestry Disability Index showed that: severity of pain, personal care, sitting, standing, social life and travelling score were significantly improved $(P<0.05)$. Significant differences were also found in the Quality of Life (QOL)-SF 12 in physical domain [difference -19 (95\% $\mathrm{Cl}:-6.47,-0.43)$ ], and psychological domain [difference $-19(95 \% \mathrm{Cl}:-6.31,-0.29](\mathbf{p} \leq \mathbf{0 . 0 5})$.

Conclusion: Homoeopathic treatment has made significant improvement in the patients suffering from chronic low back pain pertaining to the symptom's severity. Further Randomised control trail can be conducted for validation of the results.

Key words: Chronic Low Back pain, Homoeopathic, Oswestry disability.

\section{Introduction:}

A recent series of papers by The Lancet has stated that the increase of disability due to lower back pain has increased so dramatically world over that it is now being called as the leading cause of disability worldwide. Lower back pain is estimated to be affecting 540 million people across the world at any given point in time, according to the study. It comes as no surprise then lower back pain is the fourth highest cause of disability in India. A survey from last year that evaluated patients who sought help for back or neck problems showed that almost three-fourth patients (73\%) had lower back problems ${ }^{1}$.

Backache is a price we pay for our upright posture. It affects about $60-80 \%$ of world population. Most patients with acute low back pain, with or without radicular symptoms, have musculoskeletal or degenerative disorders that do not require specific treatment and are often self-limited. Approximately $85 \%$ of patients with low back pain cannot be given a definitive 
diagnosis. However, the possibility of more serious abnormalities that require specific treatment should always be excluded. Although there is no evidence that back pain prevalence has increased, reported disability and absence from work due to back pain have increased significantly in the last 30 years ${ }^{2}$.

\section{Causes}

Back pain is a symptom. Common causes of back pain involve disease or injury to the muscles, bones, and/or nerves of the spine. Pain arising from abnormalities of organs within the abdomen, pelvis, or chest may also be felt in the back. This is called referred pain. Many disorders within the abdomen, such as appendicitis, aneurysms, kidney diseases, kidney infection, bladder infections, pelvic infections, ovarian disorders, uterine fibroids, and endometriosis among others, can cause pain referred to the back. Normal pregnancy can cause back pain in many ways, including stretching ligaments within the pelvis, irritating nerves, and straining the low back. Additionally, the effects of the female hormone estrogen and the ligament-loosening hormone relax may contribute to loosening of the ligaments and structures of the back ${ }^{3}$.

The goals of treating chronic low back pain often change over time, shifting from the initial intent to cure to improving pain and function. Patients often have unrealistic expectations of complete pain relief and full return to their previous level of activity. There is often a large gap between a patient's desired amount of pain reduction and the minimum percentage of improvement that would make a treatment worthwhile. Documenting goals and expectations and revisiting them on follow-up visits may be helpful. Patients should receive information about effective self-care options and should be advised to remain active (because muscles that do not move can eventually become hypersensitive to pain). Assessing the response to therapy should focus on improvements in pain, mood and function ${ }^{4}$.
There was a study conducted on Factors Influencing Disability due to Low Back Pain Using the Oswestry Disability Questionnaire and the Quebec Back Pain Disability Scale. The aim of this research was to compare the difference in disability caused by back pain using scores from the Oswestry Disability Questionnaire (ODQ) and the Quebec Back Pain Disability Scale (QUE) according to gender, acute and chronic low back pain (LBP) groups, specific and nonspecific LBP groups and to identify the factors influencing the degree of LBP disability. The degree of disability from back pain assessed using the ODQ score was influenced by a pain severity and LBP type. Also, QUE score was influenced by a pain severity, LBP type, pain duration and gender. To assess the disability caused by back pain accurately using the ODQ and QUE, various factors affecting the scores of the questionnaire must be considered ${ }^{5}$.

Measuring quality of life is considered as an important outcome criterion in clinical studies. Generic instruments as the Short Form 12 Health Survey offer the possibility to compare outcomes among different indications. Therefore, a test of the factorial (structural) validity of the method in each indication is necessary. This study is based upon SF-12 data from 343 patients with diabetes mellitus, which were pooled together from two rehabilitation research projects. The psychometric properties of the measure were analyzed, and the questionnaires structure was tested using confirmatory structural equation modelling. In a second step age and gender specific analyses were undertaken ${ }^{6}$.

The above studies emphasise the importance of Oswestry Disability and SF-12 health survey in clinical cases. Hence same criterion was used in this study.

Homoeopathy is increasingly becoming the treatment of choice among patients for chronic diseases. Homeopathy is a holistic system of medicine that believes that body and mind are integrated. It attempts to go to the root level of disease in each individual patient by studying the physical make-up of the patient as well as the 
intellectual and mental characteristics i.e. each patient is treated on basis of individualization. The homeopathic medicine initiates a healing process in the patient that beneficial for the overall health of the patient ${ }^{7}$.

\section{MATERIAL AND METHODS}

The study was single centre, non-randomised prospective interventional study. This study was carried out at UHC Homoeopathic OPD, Sangareddy. The study was started from Dec 2018 to Feb 2019. Before enrolment, written consent was obtained. The study designed was reviewed and Permission was granted by the college ethical committee.

Total 20 patients were screened during the study period. During this study subject of both sexes of age group between 40 to 55 years were included in the study. The subject was evaluated on SF-12 assessment questionnaires to judge the $\mathrm{QOL}$ and Oswestry Disability Index scale to assess the symptom severity.

\section{Inclusion Criteria}

- Patients of both sexes between the age group 40 to $55 \mathrm{yrs}$.

- Patients who consented to participate in the study.

- Presence of self-reported low back pain for more than 12 weeks.

Exclusion criteria

- Age $<40$ or $>55$ years

- Previous history of carcinoma, steroids, HIV.

- Weight loss

- Widespread neurological symptoms

- Structural spinal deformity

\section{Intervention}

Homoeopathic medicines either in 200 or $30 \mathrm{C}$ potencies were given according to totality of symptoms and symptom severity. The selection of medicines was arrived at by repertorising. The repertorisation was done by using the Complete Repertory in Hompath software ${ }^{8}$.

But the final selection of the medicine was done in consultation with the Materia Medica.
Homoeopathic treatment was given as per instructions given in Hahnemann's Organon of Medicine $^{9}$.

Each individual patient was prescribed a single homoeopathic medicine (by considering mental, physical generals, and particulars) of three doses (one dose comprises four globules medicated with indicated medicine).The Selection of one drug at a time, by using the 'Law of Similia Principle' and depending upon the susceptibility of the patient medicine was prescribed. If the first prescription didn't work, Investigator can change the prescription after reviewing the case. Each individual patient was followed up at 15 days of interval or early if required.

Acutely, Bryonia alba, Rhus tox, Ruta and Ledum Pal were prescribed during acute phase if the condition did not improve within 6-8 days after prescribed individualised medicine. All medicines were procured from GMP certified pharmaceutical companies approved by the College ethical Committee. And traditional management (analgesics) was tapered.

\section{Outcomes}

The primary outcome was to improve the symptoms by reducing the pain or symptoms at the end of 90 days of treatment. The secondary outcome was to assess the quality of life of patients treated with homoeopathic medication by using SF-12 health status questionnaires for quality of life.

Assessment criteria: Oswestry disability index (ODI) being the gold standard of low back functional for severity of pain outcome and SF-12 questionnaire scale for quality of life were used as subjective assessment criteria.

Oswestry Disability Index= ODI is a validated self-report questionnaire that is composed of 10 sections (questions). Each question is rated on 6point (0-5) scale measuring activities like personal care, sleep, social life etc.

The completed data i.e., SF-12 and ODI scale were collected and the data of 20 patients was entered into Microsoft Excel. Descriptive 
statistics were used for analysis of data. Total 20 patients, 7 (35\%) are male while 13 Consultant statistician performed the analysis of $\quad(65 \%)$ were females. There was $6(30 \%)$ subject data by using graphpad prism8 software.

\section{Results}

The study was conducted during the month of Dec to Feb 2019, 20 patients were included in this trail.

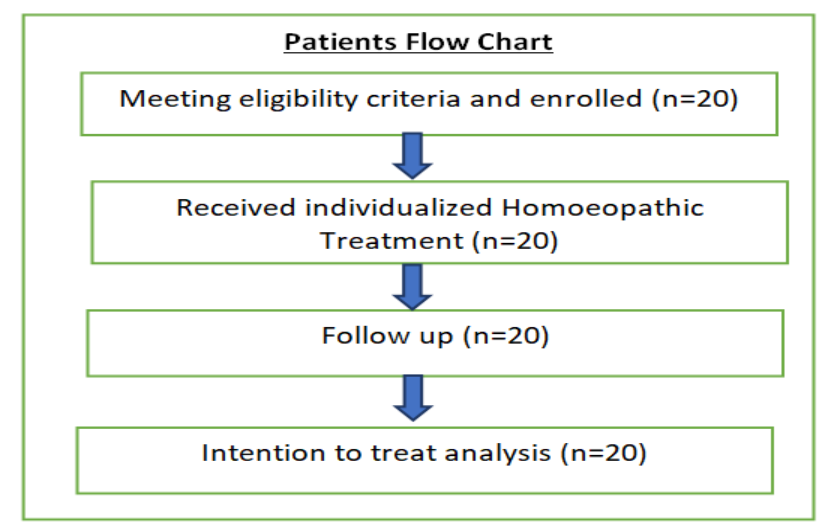
from 40 to 45 years, 6 (30\%) subjects from 46 to 50 years of age, 8 (40\%) subjects from 51 to 55 years of age. The SF-12 questionnaire, physical domain and psychological domain were statistically significantly $(P<0.001)$ (Table 2$)$. The most commonly prescribed medicine was Lycopodium was prescribed in eight patients, Nux Vomica was prescribed in six patients, Calc Carb and Phosphorus each were prescribed in three patients; Ruta and Bryonia alb each were prescribed at 9 occasions; Rhus tox was indicated in eight patients; Calcarea Flour was prescribed in 5 occasions, Ledum Pal was prescribed at 2 occasions (Figure 2).

Figure 1: Shows the patients flow chart.

Table 2: Physical Domain (Paired Samples Test)

\begin{tabular}{|c|c|c|c|c|c|c|c|}
\hline & \multicolumn{4}{|c|}{ Paired Differences } & \multirow{3}{*}{$\mathrm{t}$} & \multirow{3}{*}{$\mathrm{df}$} & \multirow{3}{*}{ Sig. (2-tailed) } \\
\hline & \multirow{2}{*}{ Mean } & \multirow{2}{*}{$\begin{array}{l}\text { Std. Error } \\
\text { Mean }\end{array}$} & \multicolumn{2}{|c|}{$\begin{array}{c}\text { 95\% Confidence Interval of the } \\
\text { Difference }\end{array}$} & & & \\
\hline & & & Lower & Upper & & & \\
\hline $\begin{array}{c}90 \text { Days - } 0 \text { Day } \\
\text { Base Line }\end{array}$ & -3.45 & 1.445 & -0.43 & -6.47 & 2.388 & 19 & .027 \\
\hline
\end{tabular}

Table 2: Psychological Domain (Paired Samples Test)

\begin{tabular}{|c|c|c|c|c|c|c|c|}
\hline & \multicolumn{4}{|c|}{ Paired Differences } & \multirow{3}{*}{$\mathrm{t}$} & \multirow{3}{*}{$d f$} & \multirow{3}{*}{ Sig. (2-tailed) } \\
\hline & \multirow{2}{*}{ Mean } & \multirow{2}{*}{$\begin{array}{c}\text { Std. Error } \\
\text { Mean }\end{array}$} & \multicolumn{2}{|c|}{$95 \%$ Confidence Interval of the Difference } & & & \\
\hline & & & Lower & Upper & & & \\
\hline $\begin{array}{c}90 \text { Days -0 } \\
\text { Day Base Line }\end{array}$ & -3.30 & 1.440 & -0.29 & -6.31 & $\begin{array}{l}2.2 \\
913\end{array}$ & 19 & .033 \\
\hline
\end{tabular}




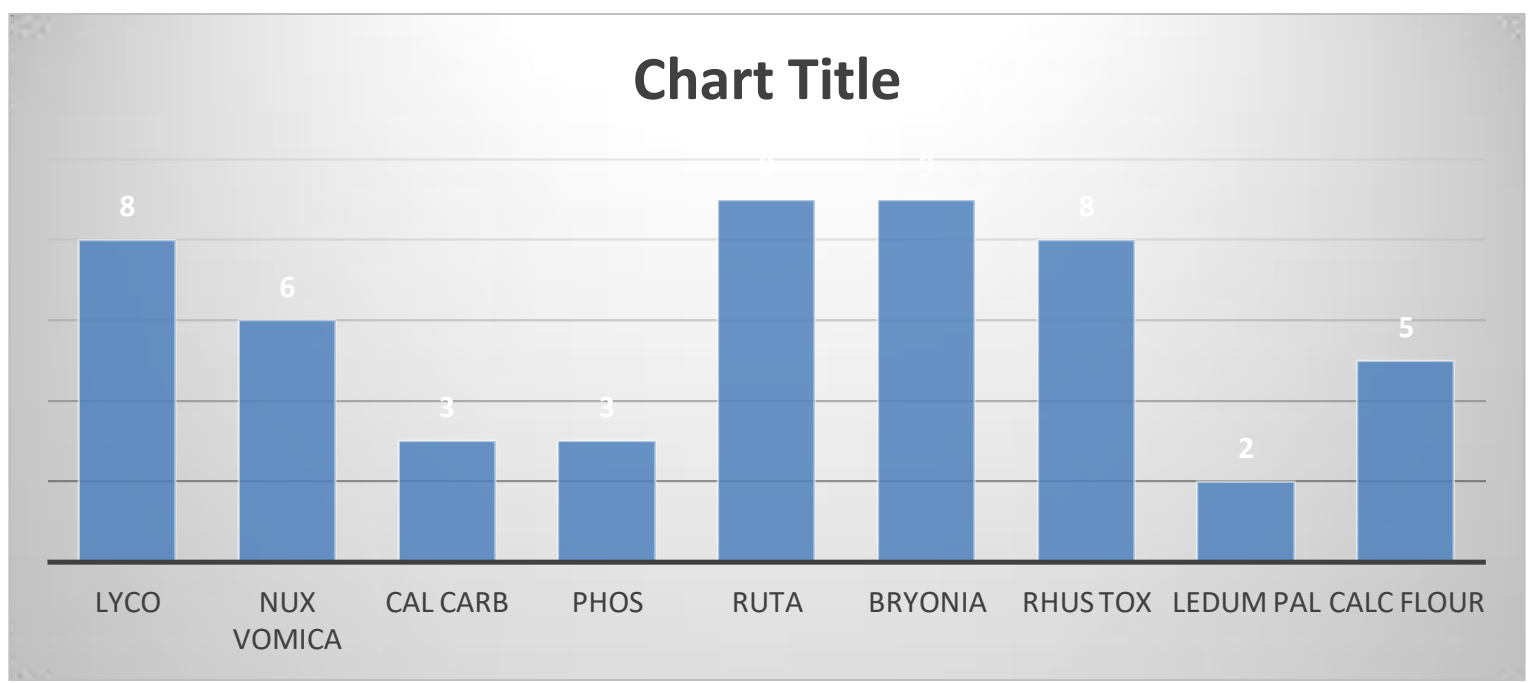

Figure 2

After 90 days of Homoeopathic treatment there was reduction was achieved in Pain Intensity, Personal Care (Washing, Dressing, etc.), Lifting, Social life and etc on Oswestry Disability Index were statistically significant. However, no statistically significant on Walking and Sleeping score Table 3.

Table 3: Oswestry Disability Index

\begin{tabular}{|l|l|l|l|l|}
\hline & Mean & N & Std. Deviation & Std. Error Mean \\
\hline 90 Days & 55.30 & 20 & 11.83 & 2.64 \\
O Day Base Line & 57.40 & 20 & 11.15 & 2.49 \\
\hline
\end{tabular}

Table 4: Paired Samples Statistics

\begin{tabular}{|c|c|c|c|c|c|c|c|}
\hline & \multicolumn{4}{|c|}{ Paired Differences } & \multirow{3}{*}{$\mathrm{t}$} & \multirow{3}{*}{$d f$} & \multirow{3}{*}{ Sig. (2-tailed) } \\
\hline & \multirow[t]{2}{*}{ Mean } & \multirow{2}{*}{$\begin{array}{l}\text { Std. Error } \\
\text { Mean }\end{array}$} & \multicolumn{2}{|c|}{$\begin{array}{l}95 \% \text { Confidence Interval of } \\
\text { the Difference }\end{array}$} & & & \\
\hline & & & Lower & Upper & & & \\
\hline $\begin{array}{l}90 \text { Days - } 0 \text { Day } \\
\text { Base Line }\end{array}$ & 2.10 & 0.83 & 0.34 & 3.86 & 2.501 & 19 & .021 \\
\hline
\end{tabular}

\section{Discussion}

This study was conducted at UHC Homoeopathic OPD sangareddy, encompassing a population from various walks of life in an urban health-care setting. Total 20 patients who completed the trial, there were 7 (35\%) males and 13 (65\%) females. It was observed in the current study that the incidence of low back pain was high amongst the elderly population between 51 to 55 years $(40 \%)$, which is considered as the postmenopausal age of a female. This correlates the incidence of the disease with menopause or impaired calcium metabolism. During this study many symptoms associated with disease such as gastritis (APD) (12 patients), sleeplessness (8 patients), cervical spondylitis (5 patients), frequency of urination ( 2 patients), constipation (11 patients).

To assess the efficacy of the Homoeopathic medicine was done by evaluating the difference 
in mean and percentage change of grades in the SF-12 questionnaire score and in the grade/severity of the various symptoms by comparing at baseline score and at 90 days. Mean, Standard deviation, $p$ values and percentage changes from base line till 90 days were calculated to arrive to conclusions. It was observed that there was a statistically significant reduction in symptoms like Pain Intensity, Personal Care (Washing, Dressing, etc.), Lifting, Social life and etc. So, this therapy has no side effects for patients coming for outpatient department.

Although our findings were analysed by using data collected by self questionnaire responses in a small sample size, but mean period of treatment was 90 days and it was a satisfactory period of treatment. By this therapy with substantial relief in pain and improvement in QOL signifies the clinical effect of homoeopathic medicines.

\section{Conclusion}

This study illustrates the efficacy of homoeopathic treatment in chronic low back pain. The present study confirms the efficacy and safety of Homoeopathic treatment in relieving symptoms of pain intensity, social life etc. Symptoms such as Pain Intensity, Personal Care (Washing, Dressing, etc.), lifting weight was significantly reduced at the end of the study. Hence, it can be concluded that individualised Homoeopathic treatment can be used safely and effectively in the treatment of chronic low back pain. A randomized controlled trial is suggested further.

\section{Acknowledgement:}

I sincerely acknowledge our Management and the Principal MNR Homoeopathic Medical
College and Hospital, Sangareddy for their support.

\section{Reference:}

1. https://www.indiatimes.com/health/healthy living/73-of-patients-with-spine-problemshave-lower-back-pain-here-s-everythingyou-need-to-know-354911.html.

2. Pradeep Kumar Maheshwari, Anjana Pandey Rosmy Jose, Practical Approach to a Person with Low Backache, chapter 33, API, http www.apiindia.org pdf progress in medicine 2017 mu 33. Pdf.

3. RK Arya, Low back pain - Signs, symptoms, and management, Journal, Indian Academy of Clinical Medicine,Vol. 15, No. 1, JanuaryMarch, 2014.

4. Allen r. Last and Karen Hulbert, Chronic Low Back Pain: evaluation and management, American Family Physician, June, 15, 2009,volume 79, number 12, 1068.

5. G.-m. Kim et al, Factors Influencing Disability due to Low Back Pain Using the Oswestry Disability Questionnaire and the Quebec Back Pain Disability Scale, Physiotherapy Research International . May 2014, https://www.researchgate.net/publication/2 62001223.

6. C. Maurischat, P. Herschbach, A. Peters \& M. Bullinger, Factorial validity of the Short Form 12 (SF-12) in patients with diabetes mellitus, Psychology Science Quarterly, Volume 50, 2008 (1), p. 7-20.

7. Ullman Dana. A Homeopathic Perspective on Psychological Problems: Treating Mind and Body. Homeopathic Journal: Volume: 2, Issue: 7, May 2009. Available at Homeorizon.com.

8. Jawahar Shah. Hompath Classic Ver 8.0. Complete Repertory. Hahnemann S; Organon of Medicine; Reprint $6^{\text {th }}$ edition. New Delhi: B Jain Publishers; 1982: p 290. 